\title{
POLYCHLORINATED BIPHENYLS IN FISHES FROM BULGARIAN BLACK SEA COAST
}

\author{
Rizov T., M. Stancheva, L. Makedonski \\ Department of Chemistry, Medical University - Varna
}

Reviewed by: assoc. prof. D. Dimitrov

\begin{abstract}
The concentrations of polychlorinated biphenyls (PCBs) were determined in fish species from Bulgarian Black Sea coast. It had selected three of the most popular fish species in our country - european sprat (Spr. Sprathus Sullinig), Black Sea goby (Neogobius Melanostomu) and Mediterranean horse mackerel - scad (Trachurus Mediterraneus). The fish samples were collected from the region of Varna in year 2003 - 2005 and the edible tissues of the fish species were investigated. The fourteen congeners of PCB were analyzed including the set of 7 indicators PCBs (IUPAC № 28, 52, 101, 118, 138, 153, 180) with Gas Chromatography Mass Spectroscopy method. PCBs were found in all investigated samples. European sprat showed the highest total level of PCBs (187.9 - 220,1 $\mathrm{ng} / \mathrm{g}$ fat) compared to the other species - goby $(66.3$ - $192.2 \mathrm{ng} / \mathrm{g}$ fat) and horse mackerel (14.7 - 208.2 ng/g fat). The highest level of PCBs was found in year 2005. Our study illustrated that the concentration level of PCBs in analyzed samples was lower compared with those recommended by different European institutions.
\end{abstract}

Key words: polychlorinated biphenyls (PCBs), fish, Bulgarian Black Sea coast

\section{INTRODUCTION}

Polychorinated biphenyls (PCBs) are organic chemicals with common characteristics to organochlorine pesticides (OCPs). They were produced comercially by catalytic chlorination of biphenyls, producing a complex mixture of multiple isomers with different degrees of chorination yielding up to 209 products called congeners. PCB congeners with the same number of chorine atoms are known as homologs and the homologs with different chlorine positions are called isomers.

PCBs were produced from 1930s with particularly large amount up to 1970s and they were used in a wide range of industrial applications due to their excellent physical and chemical properties - thermal stability, chemical inertness, non-flammability, high electrical resistivity.

In 1970s the first evidence was published about detrimental effects on organisms and the environment as a whole. Part of them are potential causes of cancer and have a negative effect on the endocrine, reproductive and the neurological systems $(5,10,15,17)$. Due to toxic effects in humans and aquatic organisms, the use and sale of most OCPs and

Address for correspondence:

L. Makedonski, Dept. of Chemistry, Faculty of Pharmacy, Medical University Prof. Dr. Paraskev Stoyanov, 55 Marin Drinov St., 9002, Varna, BULGARIA

Bulgaria phone +359 52677074

e-mail: lubomir60@yahoo.com
PSBs has been banned or restricted in many European countries since the mid 1970s.

Today it is known that PCB and OCP are ubiquitous and persistent environmental pollutants with a well known potential toxicity. They may bioaccumulate in the aquatic food web and have been of great concern due to their toxic effects on wildlife and human health. A number of studies $(2,3,4,8,11,13,18,19)$ have shown that the major food sources of these organic pollutants are fat-containing animal products including fish and other seafood. Fish is a suitable indicator for the environmental pollution monitoring because they concentrate pollutants in their tissues. Therefore fish consumption may be a risk for human health, especially for resident population.

Black Sea is a unique ecosystem because it is an inner sea with low salinity, half-isolated from the Mediterranean with hydrology and phytobentos different from the other seas in the same biogeographic region. It is bordered by Bulgaria, Romania, Ukraine Russia, Georgia and Turkey and receives fresh water input from some of the largest rives in Europe (the Danube, Dniester and Dnieper). At least 170 million people live in the Black Sea basin. Although, some studies have assessed the environmental quality of Black Sea $(1,7,9,16)$. Data about the current contamination of PSBs and OCPs are very scarce, no systematic measurements in biological samples. Therefore, comprehensive studies are needed to understand the status of contamination and pollution of these chemicals in the Black Sea. 
The aim of this study was to assess the status of PCBs contamination in fish species from Bulgarian Black Sea coast, region of Varna (Figure 1).

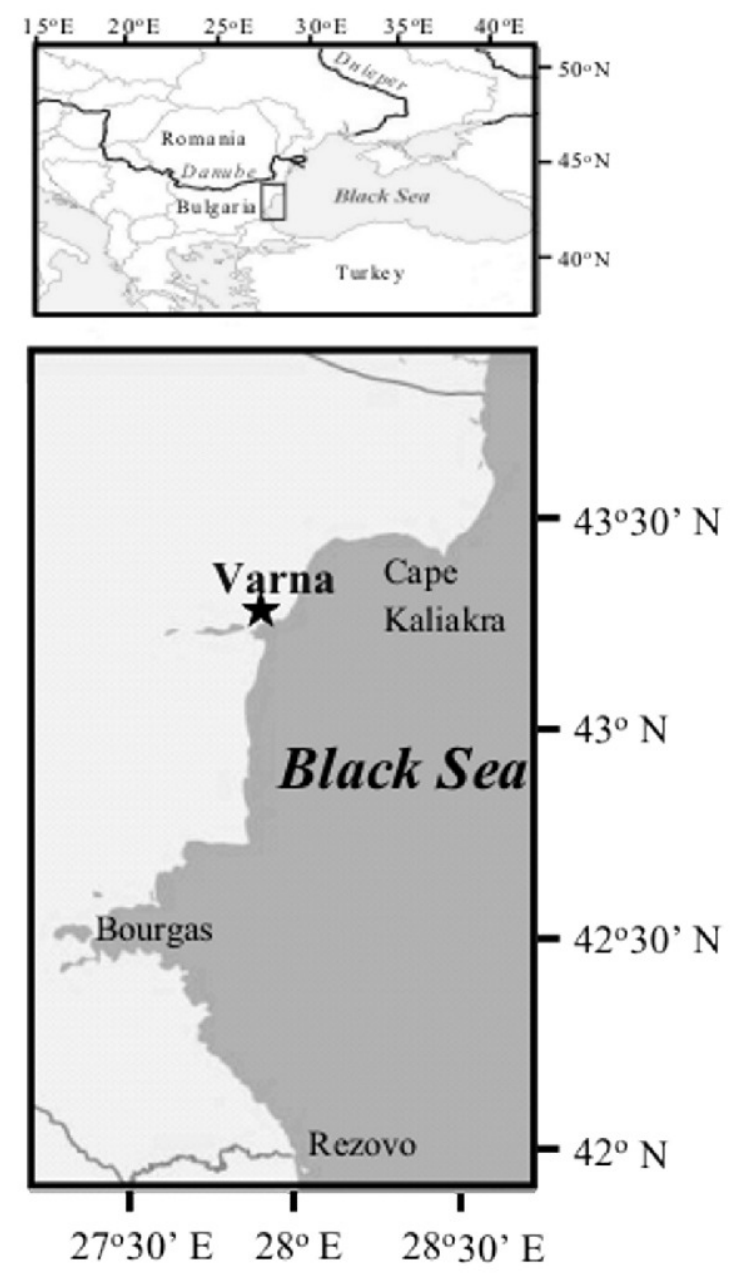

Figure 1. Black Sea and Bulgarian coast

\section{EXPERIMENTAL}

\section{Sampling}

We had selected three of the most consumed fish species in our country-european sprat (Spr. Sprathus sullinig), Black Sea goby (Neogobius melanostomu) and Mediterranean horse mackerel - scad (Trachurus mediterraneus). The samples were collected from fishermen and fish markets in the period of year 2003 and 2005. The volume of the collected fish samples ranged from $1.0 \mathrm{~kg}$ to $2 \mathrm{~kg}$. The transportation to the laboratories has been done by means of fridge bags and the storage in the laboratories was done in a freezer at temperatures lower than $-10^{\circ} \mathrm{C} .0 .5 \mathrm{~kg}$ of edible fish tissue was ground and homogenized and then an average sample was taken and analyzed.

\section{Sample treatment}

Sample preparation includes extraction of fat with a mixture of n-hexane/ dichloromethane (3:1 v/v) after addition of internal standards PCB 30 and PCB 204. Further cleanup and lipid removal are achieved by using acid and basic modified silica gel multiplayer columns. The sample was concentrated on a rotation vacuum evaporator at a temperature $35-40^{\circ} \mathrm{C}$.

\section{Analytical determination}

The analysis of PCBs is performed by GC Perkin Elmer Autosystem XL coupled to ECD and a mass spectrometer. The column was $60 \mathrm{~m}$ long and internal diameter $0.25 \mathrm{~mm}$ and film thickness RTX-5 $-0.25 \mu \mathrm{m}$, detector temperature $310^{\circ} \mathrm{C}$, injector split/splitters at a temperature $250^{\circ} \mathrm{C}$. Carrier gas helium at a speed $30 \mathrm{~cm} / \mathrm{min}$, temperature programme: $120^{\circ} \mathrm{C}$, increase by $20^{\circ} \mathrm{C} / \mathrm{min}$ up to $320^{\circ} \mathrm{C}$ and retention $15 \mathrm{~min}$. The parameters of the methods are the following: limit of detection $0.1-0.3 \mathrm{ng} / \mathrm{g}$ fat, analytical recovery 59 - $65 \%$; variation coefficient \pm 23 - $28 \%$.

The fourteen congeners of PCBs were analyzed including the set of 7 indicators (PCBs 28, 52, 101, 118, 138, 153, 180).

\section{RESULTS AND DISCUSSION}

PCBs were determined in the different fish species from Varna region during the period of 2003 and 2005. The profiles of the 14 analyzed PCB congeners and the total of their concentrations ( $\Sigma \mathrm{PCBs}$ ) are presented in Table 1. There is a clear evidence that $\Sigma$ PCBs concentrations expressed as a lipid basis (ng/g fat) is largest in year 2005 while year 2003 showed the minimum concentration for all investigated fish samples. European sprat shows the highest levels of PCBs (187,9-220,1 ng/g fat) compared to the other species: goby (66,3 - 71,5 ng/g fat) and Mediterranean horse mackerel $\operatorname{scad}(14,7-208,2 \mathrm{ng} / \mathrm{g}$ fat).

European sprat: It has showed the highest PCB congeners in year 2003: 8 fish species. Number 52 (23.3 ng/g fat) and $118(22.9 \mathrm{ng} / \mathrm{g}$ fat $)$ which are indicators showed higher concentrations while numbers 105 (43.8 ng/g fat) and 169 (47.7 ng/g fat) have the highest values of concentrations (dioxin-like PCBs).

There is a new PCB (number 28) in year 2004 which has showed the highest value for that year $(21.9 \mathrm{ng} / \mathrm{g}$ fat). That is why we had investigated a higher degree of pollution. The individual PCBs for year 2004 are only three compared with year 2003. In year 2005 the concentration of number 28 has been increased with a value of $61.0 \mathrm{ng} / \mathrm{g}$ fat and a new PCB with a number 180 has been appeared (50.4 $\mathrm{ng} / \mathrm{g}$ fat) . PCBs with numbers 28,118 and 180 are with high concentration for year 2005 and altogether they determined the biggest pollution in year 2005 .

Black Sea goby: Only two congeners of polychlorinated biphenyls are found in year 2003 - number 77 (49.4 ng/g fat) and number 101 (16.9 ng/g fat). Number 77 is the main environmental pollutant and it had been disappeared in the following years. Numbers 101 decreases its concentration in year 2004 and slightly increases in year $2005(23.4 \mathrm{ng} / \mathrm{g})$. In year 2004 and 2005 four congeners can be found with highest concentration of number 156 (32.8 ng/g fat) for year 2004 that determined the pollution in this year. Year 
2005 has highest values of congeners with numbers 101 (23.4 ng/g fat) and number 138 (42.3 ng/g fat)

Mediterranean horse mackerel: In year 2003 and 2004 the total concentrations ( $\mathrm{PCB}$ ) of PCBs is low compared to the values in year 2005 and it is due to different congeners (14.7 ng/g fat respectively $5 \mathrm{ng} / \mathrm{g}$ fat). The PCB profiles in 2005 are determined only of individual PBCs with number 28 (169.0 ng/g fat) and 138 (39.2 ng/g fat) which are 'target' congeners.

Figure 2 illustrate the comparison of fourteen analyzed congeners $\Sigma$ PCBs (ng/g fat) and seven indicators $\Sigma *$ PCBs (ng/g fat) in fish samples. The observed high values of $\Sigma$ PCBs are due mainly to the indicators PCBs covering the
$\mathrm{PCB}$ s is much higher than the values of fish species from Black sea obtained in our study.

PCB concentrations were also determined as ng/g product. (Table 1). The results are in good agreement with the data for fish species from Ceyhan river basin located in the eastern Mediterranean region of Turkey (9) and lower than the results showed in the Danube Delta, Romania (7).

OCPs are also determined for the same fish species as the ones describe above (14). Figure 3 showed the comparison of $\Sigma$ PCBs and $\Sigma$ DDT (ng/g fat) in those fish samples. The results demonstrated that high values of $\mathrm{PCB}$ correlate with low concentrations of DDT and vise versa.

The European Union has set with the directive 1999/ 788/CE

Table1. Concentration of individual PCBs congeners and $\Sigma P C B s[n g / g$ fat] in fish samples

\begin{tabular}{|c|c|c|c|c|c|c|c|c|c|}
\hline & \multicolumn{3}{|c|}{ European Sprat } & \multicolumn{3}{|c|}{ Black Sea Goby } & \multicolumn{3}{|c|}{ Mediter. horse mackerel/scad/ } \\
\hline & 2003 & 2004 & 2005 & 2003 & 2004 & 2005 & 2003 & 2004 & 2005 \\
\hline Fat $\%$ & 16.00 & 6.69 & 14.79 & 2.50 & 3.42 & 1.38 & 21.15 & 17.08 & 2.59 \\
\hline \multicolumn{10}{|l|}{ PCB } \\
\hline $28^{*}$ & - & 21.9 & 61.0 & - & - & 0.2 & 2.7 & - & 169.0 \\
\hline 31 & 6.9 & - & 28.6 & - & 7.5 & - & 11.4 & - & - \\
\hline $52 *$ & 23.3 & - & - & - & - & - & - & 1.2 & - \\
\hline 77 & 21.1 & - & - & 49.4 & - & - & - & 0.2 & - \\
\hline $101 *$ & 13.7 & 1.3 & - & 16.9 & 3.9 & 23.4 & 0.4 & - & - \\
\hline 105 & 43.8 & - & 4.4 & - & - & - & - & - & - \\
\hline $118^{*}$ & 22.9 & - & 75.7 & - & - & - & - & 3.4 & - \\
\hline 126 & - & - & - & - & - & - & - & - & - \\
\hline 128 & 8.5 & 0.3 & - & - & 3.0 & - & - & 0.2 & - \\
\hline $138^{*}$ & - & - & - & - & - & 42.3 & - & - & 39.2 \\
\hline $153^{*}$ & - & - & - & - & - & 5.6 & - & - & - \\
\hline 156 & - & - & - & - & 32.8 & - & - & - & - \\
\hline 169 & 47.7 & - & - & - & - & - & 0.2 & - & - \\
\hline $180 *$ & - & - & 50.4 & - & - & - & - & - & - \\
\hline$\Sigma$ PCBs [ng/g fat] & 187.9 & 23.5 & 220.1 & 66.3 & 47.2 & 71.5 & 14.7 & 5.0 & 208.2 \\
\hline$\Sigma \mathrm{PCBs}^{*}[\mathrm{ng} / \mathrm{g}$ fat $]$ & 59.9 & 23.2 & 187.1 & 16.9 & 3.9 & 71.5 & 3.1 & 4.6 & 208.2 \\
\hline$\Sigma D D T$ [ng/g fat] & 60.53 & 74.05 & 49.85 & 18.31 & 70.02 & 55.40 & 82.61 & 125.07 & 32.26 \\
\hline
\end{tabular}

* indicators PCBs ("target")

three fish species. Naso at all has investigated 10 fish species from Gulf of Naples, Southern Italy (12) and the
(6) a maximum content of $200 \mathrm{ng} / \mathrm{g}$ lipid basis, calculated as the sum of concentration of the seven "target" congeners 


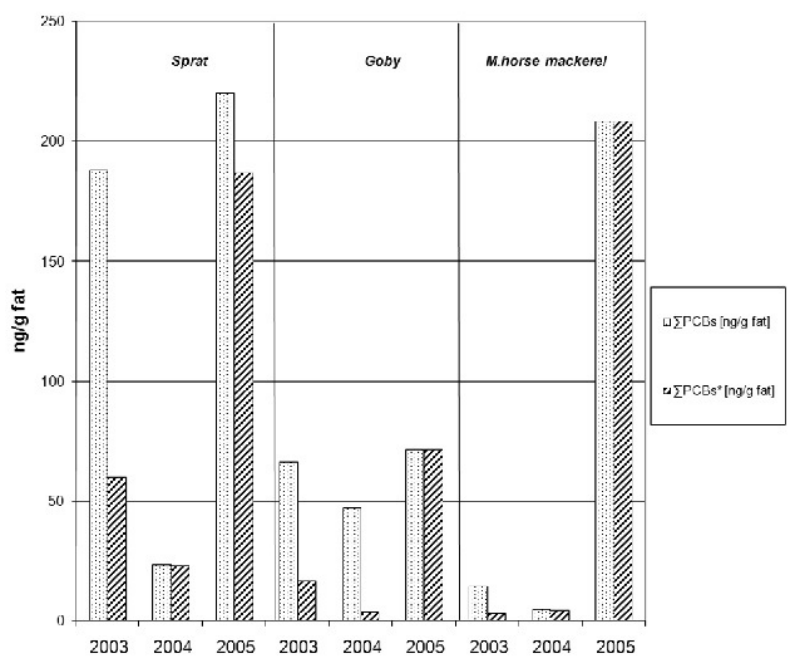

Figure 2. Comparison of $\Sigma$ PCBs and indicators $\Sigma$ PCBs [ng/g fat] in fish samples

(PCB 28, PCB 52, PCB 101, PCB 118, PCB 138, PCB 153 and PCB 180) in meat, poultry and derived products, but not in fish. In our case, as shown in Table 1, the mean PCB concentration expressed on lipid basis and as the sum of the seven "target" congeners indicated by the EU, are within the above mentioned limits. On this basis the most important problem is, as soon as possible, to set limits for PCBs in seafood, which are the main source of human exposure to these toxic compounds within the European Union.

\section{CONCLUSION}

- Concentrations of PCBs were detected in all analyzed samples

- The highest levels of PCBs were found in 2005 for the all fish species

- European sprat showed the highest content PCBs (187,9 - 220,1 ng/g fat) compared to the other species - gobies (66,3 - 192,2 ng/g fat) and scad (14,7 - 208,2 ng/g fat)

- The comparison of content PCBs and DDT showed opposite correlation

\section{ACKNOWLEDGMENT}

This study was financed by the National Science Fund, Ministry of Education and Science of Bulgaria (Project DVU 440/2008).

\section{REFERENCES}

1. Bakan, G., S. Ariman, Persistent organochlorine residues in sediments along the coast of mid-Black Sea region of Turkey, Marine Pollution Bulletin, 48, 1031 (2004).

2. Bayarri, S., L. Baldassarri, N. Iacovella, F. Ferrara, A. Domenico, PCDDs, PCDFs, PCBs

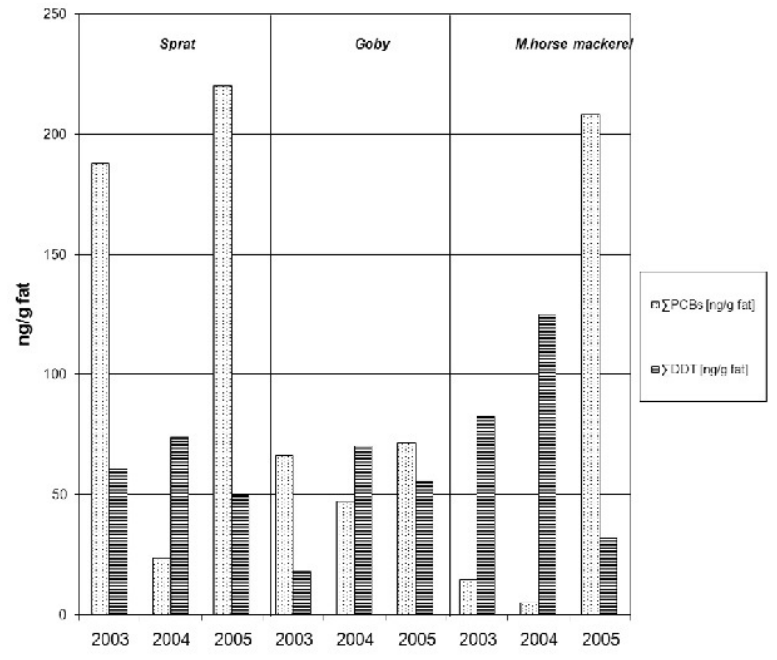

Figure 3. Comparison of $\Sigma P C B$ s and $\Sigma D D T$ [ng/g fat] in fish samples

and DDE in edible marine species from the Adriatic Sea, Chemosphere, 43, 601 (2001).

3. Binelli, A., F. Riccardi, A. Provini, Present status of POP contamination in Lake Maggiore (Italy), Chemosphere, 57, 27 (2004).

4. Bocio, A., J. Domingo, G. Falco, J. Llobet, Concentrations of PCDD/PCDFs and PCBs in fish and seafood from the Catalan (Spain) market: Estimated human intake, Environment International, 33, 170 (2007).

5. Borja, J., D. Taleon, J. Auresemia, S. Gallardo, Polychlorinated biphenyls and their biodegradation, Process Biochemistry, 40, 1999 (2005).

6. Commission of the European Communities, G.U. EU-L 310/62 of 04/12/199

7. Covaci, A., A. Gheorge, O. Hulea, P. Schepens, Levels and distribution of organochloride pesticides, polychlorinated biphenyls and polybrominated diphenyl ethers in sediments and biota from the Danube Delta, Romania, Environmental Pollution, 140, 136 (2006).

8. Domingo, J., A. Bocio, Levels of PCDD/PCDFs and PCBs in edible marine species and human intake: A literature review, Environment International, 33, 397 (2007).

9. Erdogrul, Ö., A. Covaci, P. Schepens, Levels of organochlorine pesticides, polychlorinated biphenyls and polybrominated diphenyl ethers in fish species from Kahramanmaras, Turkey, Environment International, 31, 703 (2005).

10. Llobet, J., J. Domingo, A. Bocio, C. Casas, A. Teixido, L. Müller, Human exposure to dioxins through the diet in Catalonia, Spain: carcinogenic and non-carcinogenic risk, Chemosphere, 50, 1193 (2003).

11. Llobet, J., J. Domingo, A. Bocio, C. Casas, A. Teixido, L. Müller, Levels of polychlorinated biphenyls in foods from Catalonia, Spain: estimated dietary intake. J. Food Protect, 66, 479 (2003).

12. Naso, B., D. Perrone, M.C.Ferrante, M.Bilancione, A.Lucisian, Persistent organic pollutants in edible marine species from the Gulf of 
Naples, southern Italy, Science of the Total Environment, 343, (2005).

13. Serrano, R., M. Barred, E. Pitarch, Determination of low concentrations of organochlorine pesticides and PCBs in fish feed and fish tissues from aquaculture activities by gaschromatography with tandem mass spectrometry, Journal of Separation Science, 26, 75 (2003).

14. Stoichev, T., L. Makedonski, T. Trifonova, M. Stancehva, F. Ribarova, DDT in fish from the Bulgarian region of the Black Sea, Chemistry and Ecology, 23, 3, 191-200 (2007).

15. Storelli, M., G. Barone, R. Garofalo, G. Marcotrigiano, Metals and organochlorine compounds in eel (Anguilla anguilla) from the Lesina la- goon, Adriatic Sea (Italy), Food Chemistry, 100, 1337 (2007).

16. Tanabe, S., A. Ozturk, A. Tatsukawa, N. Miyazaki, Isomer-specific analysis of polychlorinated biphenyls in harbour porpoise (Phocoena phocoena) from the Black Sea, Marine Pollution Bulletin, 34, 712 (1997).

17. Tanabe, S., H. Iwata, R. Tatsukawa, Global contamination by persistent organochlorines and their ecotoxicological impact on marine mammals, Sci. Total Environment, 154, 163 (1994).

18. Turk, J. and A. Turk, Environmental Science, (College Publishing, New York, 1988).

19. Yasumura, K., E. Kitamura, M. Uno, M. Tamaki, Automated Analysis for Determination of PCBs in Fish, J. Food Hyg. Soc. Japan, 42, 1 (2001). 